Jurnal Sulolipu : Media Komunikasi Sivitas Akademika dan Masyarakat

Vol. 19 No.2 2019

e-issn : 2622-6960, p-issn : 0854-624X

\title{
FAKTOR-FAKTOR DALAM KEPEMILIKAN JAMBAN KELUARGA TERHADAPKEBIASAAN BUANG AIR BESAR DISEMBARANG TEMPAT DI DESA BULU ULAWENG KECAMATAN PATIMPENG KABUPATEN BONE
}

${ }^{1}$ La Taha dan ${ }^{2}$ Hastikawati

1,2 Jurusan Kesehatan Lingkungan Poltekkes Kemenkes makassar

hastika6693@gmail.com)

\begin{abstract}
Disposal ofhumanfecesis an important part of environmental sanitation. Disposal of human faeces that do not meet sanitary requirements can lead to soil contamination and clean water supply, and trigger vector-borne diseases, such as flies, rats or other insects to nest, breed and spread diseases. The study aims to know the linkage of knowledge, attitudes, education and incomes with family latrine ownership against bowel habits everywhere in the village of Bulu Ulaweng Patimpeng District of Bone County. The type of research is descriptive research, which becomes the population is the head of the family of 179 families and the sample is 99 families. The results showed that from 99 respondents there were $70.7 \%$ of high knowledge and $29.3 \%$ were low knowledge, $80.8 \%$ were good and $19.2 \%$ were bad, $15.2 \%$ were highly educated and $84,8 \%$ are low educated, $1 \%$ each having high and high income, $18.2 \%$ are middle income and $79.8 \%$ are low income. Based on the results of the research it can be concluded that the level of knowledge and attitudes have a link to the ownership of family latrines. While the level of education and income have no relation to the ownership of family latrines.
\end{abstract}

Keywords:Latrines,Knowledge, Attitudes, Education, Income

\section{ABSTRAK}

Pembuangan tinja manusia merupakan bagian yang penting dalam sanitasi lingkungan. Pembuangan tinja manusia yang tidak memenuhi syarat sanitasi dapat menyebabkan terjadinya pencemaran tanah serta penyediaan air bersih, dan memicu hewan vektor penyakit, misalnya lalat, tikus atau serangga lain untuk bersarang, berkembang biak serta menyebarkan penyakit. Penelitian bertujuan untuk mengetahui keterkaitan pengetahuan, sikap, pendidikan dan pendapatan masyarakat dengan kepemilikan jamban keluarga terhadap kebiasaan buang air besar disembarang tempat di Desa Bulu ulaweng Kecamatan Patimpeng Kabupaten Bone. Jenis penelitian yaitu penelitian deskriptif, yang menjadi populasi adalah kepala keluarga yaitu 179 KK dan jumlah sampel yaitu 99 KK. Hasil penelitian menunjukkan bahwa dari 99 responden ada 70,7 \% yang berpengetahuan tinggi dan $29,3 \%$ yang berpengetahuan rendah, 80,8 \% yang bersikap baik dan 19,2\% yang bersikap buruk, 15,2 \% yang berpendidikan tinggi dan 84,8 \% yang berpendidikan rendah, masing - masing $1 \%$ yang berpendapatan sangat tinggi dan tinggi, 18,2 \% yang berpendapatan sedang serta $79,8 \%$ yang berpendapatan rendah. Berdasarkan hasil penelitian maka dapat diambil kesimpulan bahwa tingkat pengetahuan dan sikap memiliki keterkaitan terhadap kepemilikan jamban keluarga.Sedangkan tingkat pendidikan dan pendapatan tidak memiliki keterkaitan terhadap kepemilikan jamban keluarga.

Kata kunci :Jamban, Pengetahuan, Sikap, Pendidikan, Pendapatan

\section{Pendahuluan}

Kesehatan lingkungan menurut WHO yaitu suatu keseimbangan ekologi yang harus ada antara manusia dan lingkungannya agar dapat menjamin keadaan sehat dari manusia (Juli Soemirat Slamet, 1994).Adapun ruang lingkup kesehatan lingkungan yaitu perumahan, pembuangan kotoran manusia (tinja), penyediaan air bersih, pembuangan sampah, pembuangan air limbah, sanitasi tempat-tempat umum dan sebagainya.

Untuk mencapai derajat kesehatan yang setinggi-tingginya, maka lingkungan yang buruk harus diperbaiki. Untuk meningkatkan derajat kesehatan masyarakat dapat dilakukan beberapa upaya salah satunya yaitu dengan cara meningkatkan sanitasi dan kesehatan lingkungan. Salah satu contoh masalah sanitasi yaitu mengenai pembuangan tinja (jamban keluarga).

Keberadaan jamban di Indonesia menurut data Bank Dunia tahun 2010 (dalam Otik Widyastutik, 2016) sekitar 22\%. Secara nasional, untuk daerah perkotaan yaitu $79 \%$ dan untuk daerah pedesaan $49 \%$. Sebagian besar pembuangan tinja masih dilakukan ke sungai atau mempergunakan sumur galian yang tidak memenuhi persyaratan sehingga mencemari air tanah.

Adapun faktor-faktor yang mempengaruhi kepemilikan jamban keluarga adalah perilaku (sikap, pengetahuan dan tindakan), yang ditunjang dengan pendidikan, pendapatan, kebiasaan, pekerjaan dan sebagainya.

\section{BahandanMetode}

1. LokasiPenelitian Lokasi penelitian dilaksanakan di Desa Bulu Ulaweng Kecamatan Patimpeng Kabupaten Bone.

Waktu penelitian yang digunakan dibagi menjadi dua tahap, antara lain :

a. Tahap persiapan, meliputi tahap observasi atau pengambilan data awal yang bersumber dari Puskesmas Patimpeng serta 
Jurnal Sulolipu : Media Komunikasi Sivitas Akademika dan Masyarakat

Vol. 19 No.2 2019

e-issn : 2622-6960, p-issn : 0854-624X

$\begin{array}{lcr}\text { persiapan } & \text { proposal } & \text { dan } \\ \text { pelaksanaan } & \text { proposal } & \text { yang } \\ \text { dilaksanakan } & \text { di } & \text { kampus }\end{array}$

Politeknik Kesehatan Makassar

Jurusan Kesehatan Lingkungan

yang dilaksanakan pada bulan November 2017 - Januari 2018.

b. Tahap penelitian, meliputi pelaksanaan penelitian yang dilaksanakan pada bulan Maret 2018.

\section{Desain dan Variabel Penelitian}

Variabel Bebas adalah variabel yang dianggap berpengaruh terhadap variabel terikat, dalam hal ini adalah pengetahuan, sikap, pendidikan dan pendapatan masyarakat.Variabel Terikat adalah variabel yang dipengaruhi oleh variabel bebas, dalam hal ini adalah kepemilikan jamban keluarga. Variabel Pengganggu adalah variabel yang turut berpengaruh terhadap variabel terikat, dalam hal ini adalah kebiasaan.

3. PopulasidanSampel

\section{a. Populasi}

Populasi yang digunakan pada penelitian ini adalah kepala keluarga (KK) yang berada pada wilayah Desa Bulu Ulaweng yaitu $179 \mathrm{KK}$.

b. Sampel

Adapun jumlah sampel dalam penelitian ini yaitu $99 \mathrm{KK}$ diperoleh dengan menggunakan rumus slovin dengan pengambilan sampel secara random sampling ( acak ).

\section{Pengumpulan data}

\section{a. Data Primer}

Data primer adalah data yang diperoleh dengan melakukan observasi dan wawancara langsung dengan responden berdasarkan kuesioner yang disediakan.Data sekunder diperoleh dari berbagai referensi baik artikel-artikel, buku, literatur, dan yang lain yang dianggap dapat mendukung teori yang ada serta dianggap memiliki keterkaitan dengan penelitian ini.

b. Data Sekunder

Data sekunder juga diperoleh dari instansi yang terkait dengan penelitian ini yaitu :
a) Kantor Desa Bulu Ulaweng Kecamatan Patimpeng Kabupaten Bone.
b) Puskesmas Patimpeng Kecamatan Patimpeng
Kabupaten Bone.

\section{Analisa Data}

Pengolahan data pada penelitian ini dilakukan secara manual dengan menggunakan alat bantu komputer dan kalkulator. Data yang telah diperoleh dianalisa secara deskriptif untuk mengetahui keterkaitan variabel bebas dan variabel terikat dengan menggunakan tabel dan diuraikan dalam bentuk narasi kemudian dibuat suatu kesimpulan.

\section{HasilPenelitian}

Berdasarkan hasil penelitian yang telah di lakukan pada tanggal 29 Maret 2018 sampai 31 Maret 2018 dengan menggunakan lembar kuesioner sebanyak 99 responden di Desa Bulu Ulaweng Kecamatan Patimpeng Kabupaten Bone maka diperoleh gambaran bahwa di Desa Bulu Ulaweng yang memiliki jamban keluarga yaitu sebanyak 63 responden dan yang tidak memiliki jamban keluarga yaitu sebanyak 36 responden. Jenis jamban keluarga yang digunakan responden yaitu jamban leher angsa dan jamban cemplung.Yang menggunakan jamban leher angsa sebanyak 61 responden dan jamban cemplung hanya 2 responden.Sedangkan responden yang tidak memiliki jamban keluarga, buang air besar disembarang tempat yaitu dibelakang rumah dan sungai.

Dibelakang rumah sebanyak 30 responden dan disungai sebanyak 6 responden. Tingkat pendidikan responden yang tinggi meliputi kategori tamat SMA dan Sarjana sedangkan pendidikan yang rendah meliputi tidak tamat SD, tamat SD dan tamat SMP.Untuk pendapatan responden sebagian besar berprofesi sebagai petani, selain itu ada juga yang berprofesi sebagai PNS, karyawan, pengusaha dan URT.Wilayah di Desa tersebut berada di daerah yang cukup air sehingga jenis jamban leher angsa bagus untuk digunakan. 
Jurnal Sulolipu : Media Komunikasi Sivitas Akademika dan Masyarakat

Vol. 19 No.2 2019

e-issn : 2622-6960, p-issn : 0854-624X

\section{Tingkat Pengetahuan Responden}

Tabel 1

Distribusi Tingkat Pengetahuan Responden Di Desa Bulu Ulaweng Kecamatan Patimpeng Kabupaten Bone

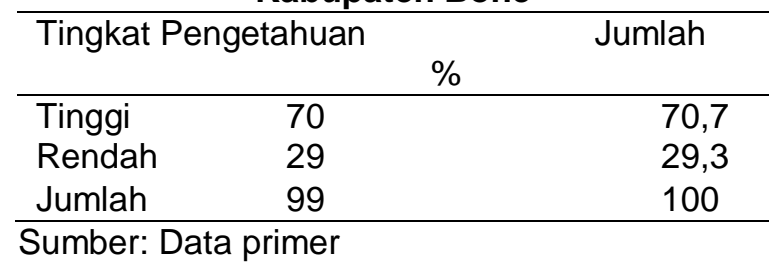

2. Tingkat Sikap Responden

Tabel 2

Distribusi Tingkat Sikap Responden Di Desa Bulu Ulaweng Kecamatan Patimpeng Kabupaten Bone

\begin{tabular}{llc}
\hline Tingkat Sikap & Jumlah & $\%$ \\
\hline Baik & 80 & 80,8 \\
Buruk & 19 & 19,2 \\
Jumlah & 99 & 100 \\
\hline
\end{tabular}

3. Tingkat Pendidikan Responden

Tabel 3

Distribusi Tingkat Pendidikan Responden Di Desa Bulu Ulaweng Kecamatan Patimpeng Kabupaten Bone

\begin{tabular}{lllll}
\hline $\begin{array}{l}\text { Tingkat } \\
\text { Pendidikan }\end{array}$ & Kategori & Jumlah & Jumlah & $\%$ \\
\hline & $\begin{array}{l}\text { Tamat } \\
\text { Tinggi }\end{array}$ & 8 & & \\
& SMA & & 15 & 15,2 \\
& Sarjana & 7 & & \\
& $\begin{array}{l}\text { Tidak } \\
\text { Tamat SD }\end{array}$ & 5 & & \\
Rendah & Tamat SD & 72 & 84 & 84,8 \\
& Tamat & 7 & & \\
& SMP & & & \\
Jumlah & & 99 & 99 & 100 \\
\hline Sumber: Data primer & & &
\end{tabular}

\section{Tingkat Pendapatan Responden}

Tabel 4

Distribusi Tingkat Pendapatan Responden Di Desa Bulu Ulaweng Kecamatan Patimpeng Kabupaten Bone

\begin{tabular}{lll}
\hline Tingkat Sikap & Jumlah & $\%$ \\
\hline Sangat Tinggi & 1 & 1,0 \\
Tinggi & 1 & 1,0 \\
Sedang & 18 & 18,2 \\
Rendah & 79 & 79,8 \\
Jumlah & 99 & 100
\end{tabular}

Sumber: Data Primer

5. Kepemilikan Jamban Keluarga

Tabel 5

Distribusi Kepemilikan Jamban Keluarga Responden Di Desa Bulu Ulaweng Kecamatan Patimpeng Kabupaten Bone

\begin{tabular}{lll}
\hline Kepemilikan Jamban & Jumlah & $\%$ \\
\hline Memiliki & 63 & 63,6 \\
Tidak Memiliki & 36 & 36,4 \\
Jumlah & 99 & 100 \\
\hline
\end{tabular}

Sumber: Data primer

\section{Pengaruh Tingkat Pengetahuan Terhadap KepemilikanJamban Keluarga \\ Tabel 6}

Pengaruh Tingkat Pengetahuan Responden Terhadap Kepemilikan Jamban Keluarga Di Desa Bulu Ulaweng Kecamatan Patimpeng Kabupaten Bone

\begin{tabular}{|c|c|c|c|c|c|c|}
\hline \multirow{3}{*}{$\begin{array}{c}\text { Tingkat } \\
\text { Pengetahuan }\end{array}$} & \multicolumn{4}{|c|}{$\begin{array}{c}\text { Kepemilikan Jamban } \\
\text { Keluarga }\end{array}$} & & \\
\hline & \multicolumn{2}{|c|}{$\begin{array}{l}\text { Memiliki } \\
\text { Jamban }\end{array}$} & \multicolumn{2}{|c|}{$\begin{array}{c}\text { Tidak } \\
\text { Memiliki } \\
\text { Jamban }\end{array}$} & \multicolumn{2}{|c|}{ Jumlah } \\
\hline & $\mathrm{N}$ & $\%$ & $\mathrm{~N}$ & $\%$ & $N$ & $\%$ \\
\hline Tinggi & 57 & 90,5 & 13 & 36,1 & 70 & 70,7 \\
\hline Rendah & 6 & 9,5 & 23 & 63,9 & 29 & 29,3 \\
\hline Jumlah & 63 & 100 & 36 & 100 & 99 & 100 \\
\hline
\end{tabular}


Jurnal Sulolipu : Media Komunikasi Sivitas Akademika dan Masyarakat

Vol. 19 No.2 2019

e-issn : 2622-6960, p-issn : 0854-624X

\section{Pengaruh Tingkat Sikap Terhadap KepemilikanJamban Keluarga}

Tabel 7

Pengaruh Tingkat Sikap Responden Terhadap Kepemilikan Jamban Keluarga Di Desa Bulu Ulaweng Kecamatan Patimpeng Kabupaten Bone

\begin{tabular}{ccccccc}
\hline \multicolumn{7}{c}{$\begin{array}{c}\text { Kepemilikan Jamban } \\
\text { Keluarga }\end{array}$} \\
\cline { 2 - 7 } $\begin{array}{c}\text { Tingkat } \\
\text { Sikap }\end{array}$ & \multicolumn{2}{c}{$\begin{array}{c}\text { Memiliki } \\
\text { Jamban }\end{array}$} & \multicolumn{2}{c}{$\begin{array}{c}\text { Tidak } \\
\text { Memiliki }\end{array}$} \\
& $\mathrm{N}$ & $\%$ & $\mathrm{~N}$ & $\%$ & $\mathrm{~N}$ & $\%$ \\
\hline Baik & 49 & 77,8 & 31 & 86,1 & 80 & 80,8 \\
\hline Buruk & 14 & 22,3 & 5 & 13,9 & 19 & 19,2 \\
\hline Jumlah & 63 & 100 & 36 & 100 & 99 & 100 \\
\hline Sumber:
\end{tabular}

Sumber: Data primer

\section{Pengaruh Tingkat Pendidikan Terhadap KepemilikanJamban Keluarga \\ Tabel 8 \\ Pengaruh Tingkat Pendidikan Responden Terhadap Kepemilikan Jamban Keluarga Di Desa Bulu Ulaweng Kecamatan Patimpeng Kabupaten Bone}

\begin{tabular}{|c|c|c|c|c|c|c|}
\hline \multirow{3}{*}{$\begin{array}{c}\text { Tingkat } \\
\text { Pendidikan }\end{array}$} & \multicolumn{4}{|c|}{$\begin{array}{c}\text { Pemilikan Jamban } \\
\text { Keluarga }\end{array}$} & \multirow{2}{*}{\multicolumn{2}{|c|}{ Jumlah }} \\
\hline & \multicolumn{2}{|c|}{$\begin{array}{l}\text { Memiliki } \\
\text { Jamban }\end{array}$} & \multicolumn{2}{|c|}{$\begin{array}{c}\text { Tidak } \\
\text { Memiliki } \\
\text { Jamban }\end{array}$} & & \\
\hline & $\mathrm{N}$ & $\%$ & $N$ & $\%$ & $\mathrm{~N}$ & $\%$ \\
\hline Tinggi & 13 & 20,6 & 2 & 5,6 & 15 & 15,2 \\
\hline Rendah & 50 & 79,4 & 34 & 94.4 & 84 & 84,8 \\
\hline Jumlah & 63 & 100 & 36 & 100 & 99 & 100 \\
\hline
\end{tabular}

Sumber: Data primer
9. Pengaruh Tingkat Pendapatan Terhadap Kepemilikan Jamban Keluarga
Tabel 9

Pengaruh Tingkat Pendapatan Responden

Terhadap Kepemilikan Jamban Keluarga Di

Desa Bulu Ulaweng Kecamatan Patimpeng Kabupaten Bone

\begin{tabular}{|c|c|c|c|c|c|c|}
\hline \multirow[t]{3}{*}{$\begin{array}{c}\text { Tingkat } \\
\text { Pendapatan }\end{array}$} & \multicolumn{4}{|c|}{$\begin{array}{c}\text { Kepemilikan Jamban } \\
\text { Keluarga }\end{array}$} & \multirow{2}{*}{\multicolumn{2}{|c|}{ Jumlah }} \\
\hline & \multicolumn{2}{|c|}{$\begin{array}{l}\text { Memiliki } \\
\text { Jamban }\end{array}$} & \multicolumn{2}{|c|}{$\begin{array}{c}\text { Tidak } \\
\text { Memiliki } \\
\text { Jamban }\end{array}$} & & \\
\hline & $\mathrm{N}$ & $\%$ & $\mathrm{~N}$ & $\%$ & $\mathrm{~N}$ & $\%$ \\
\hline $\begin{array}{l}\text { Sangat } \\
\text { Tinggi }\end{array}$ & 1 & 1,6 & - & - & 1 & 1 \\
\hline Tinggi & 1 & 1,6 & - & - & 1 & 1 \\
\hline Sedang & 16 & 25,4 & 2 & 5,6 & 18 & 18,2 \\
\hline Rendah & 45 & 71,4 & 34 & 94,4 & 79 & 79,8 \\
\hline Jumlah & 63 & 100 & 36 & 100 & 99 & 100 \\
\hline
\end{tabular}

\section{Pembahasan}

1. Tingkat Pengetahuan Responden Terhadap Kepemilikan Jamban Keluarga

Pengetahuan responden di Desa

Bulu Ulaweng Kecamatan Patimpeng Kabupaten Bone masih rendah serta ada keterkaitan antara tingkat pengetahuan responden terhadap kepemilikan jamban keluarga di Desa Bulu Ulaweng Kecamatan Patimpeng Kabupaten Bone. Seperti halnya dengan hasil penelitian Muh Rijaluddin (2013), bahwa tingkat pengetahuan masyarakat yang selalu memanfaatkan jamban keluarga dengan kategori baik sebanyak $86,67 \%$ responden, dan $13,13 \%$ responden yang memiliki pengetahuan kurang.

Berdasarkan hasil penelitian dari 99 responden sebagian besar memiliki pengetahuan yang tinggi meski pada tabel distribusi tingkat pendidikan (Tabel 3) sebagian besar responden memiliki pendidikan yang rendah, namun untuk mengetahui fungsi dari jamban serta dampak yang ditimbulkan jika tidak memiliki jamban dapat diketahui selain dari pendidikan formal tetapi juga dengan pendidikan non formal. Semakin tinggi pengetahuan maka semakin tinggi peluang memiliki jamban keluarga. Menurut teori 
Jurnal Sulolipu : Media Komunikasi Sivitas Akademika dan Masyarakat

Vol. 19 No.2 2019

e-issn : 2622-6960, p-issn : 0854-624X

Sudarma (2008) dalam (Suharno, 2015) bahwa pengetahuan dapat diperoleh dari pengalaman langsung ataupun pengalaman orang lain. Pengetahuan dapat ditingkatkan melalui penyuluhan, baik secara individu atau kelompok, untuk meningkatkan pengetahuan kesehatan yang bertujuan untuk tercapainya perubahan perilaku individu, keluarga dan masyarakat dalam upaya mewujudkan derajat kesehatan yang optimal.

2. Tingkat Sikap Responden Terhadap Kepemilikan Jamban Keluarga

Sikap responden di Desa Bulu Ulaweng Kecamatan Patimpeng Kabupaten Bone sudah tinggi serta ada keterkaitan antara tingkat sikap responden terhadap kepemilikan jamban keluarga di Desa Bulu Ulaweng Kecamatan Patimpeng Kabupaten Bone. Seperti halnya dengan hasil penelitian Muh Rijaluddin (2013), bahwa sikap masyarakat yang selalu memanfaatkan jamban keluarga semuanya dengan kategori baik sebanyak $100 \%$ responden.

Berdasarkan hasil penelitian dari 99 responden sebagian besar bersikap baik namun berdasarkan Tabel 7 terlihat bahwa $86,1 \%$ responden bersikap baik tetapi tidak memiliki jamban keluarga. Sehingga dapat dikatakan bahwa meskipun sikap responden baik tetapi tidak diikuti dengan praktik atau tindakan nyata, sama saja dengan sikap baik yang sia-sia. Hal ini terlihat dari teori Soekidjo Notoatmodjo (2014) dimana sikap secara nyata menunjukkan konotasi adanya kesesuain reaksi terhadap stimulus tertentu yang dalam kehidupan sehari-hari merupakan reaksi yang bersifat emosional terhadap stimulus sosial.

3. Tingkat Pendidikan Responden Terhadap Kepemilikan Jamban Keluarga

Pendidikan responden di Desa Bulu Ulaweng Kecamatan Patimpeng Kabupaten Bone masih rendah serta tidak ada keterkaitan antara tingkat pendidikan terhadap kepemilikan jamban keluarga di Desa Bulu Ulaweng Kecamatan Patimpeng Kabupaten Bone. Seperti halnya dengan hasil penelitian Muh Rijaluddin (2013), bahwa tingkat pendidikan masyarakat yang selalu memanfaatkan jamban keluarga dengan proporsi tingkat pendidikan responden yang terbesar adalah tamat SD yaitu sebanyak $75,24 \%$ responden dan tampak bahwa ada 4,28\% responden yang tamat Akademi/Perguruan Tinggi.

Berdasarkan hasil penelitian yang telah dilakukan diperoleh hasil bahwa tingkat pendidikan tidak memiliki keterkaitan dengan kepemilikan jamban keluarga.Masyarakat yang memiliki pendidikan rendah lebih banyak yang memiliki jamban keluarga dibandingkan dengan masyarakat yang memiliki pendidikan tinggi.Jadi masyarakat yang berpendidikan rendah kebanyakan yang memiliki jamban keluarga karena adanya dorongan dari keluarga besar untuk memiliki jamban keluarga serta ada bantuan dari pemerintah dengan menyediakan cetakan jamban leher angsa.Pedidikan tidak sama dengan pengetahuan, masyarakat yang memiliki tingkat pendidikan yang tinggi tidak selamanya memiliki pengetahuan yang luas bahkan ada yang memiliki pendidikan yang rendah tetapi pengetahuannya luas. Karena pengetahuan tidak hanya diperoleh dari jenjang pendidikan tetapi dapat diperoleh dari media cetak, elektronik dan penyuluhan atau mengikuti seminar. Hal itu terbukti pada waktu penelitian, responden yang memiliki tingkat pendidikan yang tinggi masih ada yang tidak memiliki jamban keluarga.

4. Tingkat Pendapatan Responden Terhadap Kepemilikan Jamban Keluarga

Pendapatan responden di Desa Bulu Ulaweng Kecamatan Patimpeng Kabupaten Bone masih rendah serta tidak ada keterkaitan antara tingkat pendapatan terhadap kepemilikan jamban keluarga di Desa Bulu Ulaweng Kecamatan Patimpeng Kabupaten Bone. Hal tersebut didasari dengan adanya sebagian besar responden yang berpendapatan rendah tetapi memiliki jamban keluarga.Meskipun pendapatan responden rendah namun kesadaran responden tentang pentingnya jamban keluarga tinggi yang menjadi motivasi untuk memiliki jamban keluarga.

Berdasarkan hasil penelitian pada Tabel 9 terlihat bahwa responden yang memiliki pendapatan sedang masih ada sekitar 5,6\% yang tidak memiliki jamban keluarga sedangkan responden yang 
Jurnal Sulolipu : Media Komunikasi Sivitas Akademika dan Masyarakat

Vol. 19 No.2 2019

e-issn : 2622-6960, p-issn : 0854-624X

berpendapatan rendah sebagian besar memiliki jamban keluarga. Hal ini berarti bahwa meskipun pendapatan rendah bukan berarti peluang memiliki jamban keluarga kecil.Pendapatan yang rendah selain memiliki kesadaran yang tinggi juga memiliki sikap dan pengetahuan yang baik, maka hal tersebut dapat menjadi motivasi untuk memilki jamban keluarga.

\section{Kesimpulan dan Saran}

1. Kesimpulan

a. Ada keterkaitan antara pengetahuan responden dengan kepemilikan jamban keluarga dengan kategori pengetahuan tinggi sebanyak $90,5 \%$ responden dan kategori pengetahuan rendah sebanyak $9,5 \%$ responden.

b. Ada keterkaitan antara sikap responden dengan kepemilikan jamban keluarga dengan kategori sikap baik sebanyak $77,8 \%$ responden dan kategori sikap buruk sebanyak $22,3 \%$ responden.

c. Tidak ada keterkaitan antara pendidikan responden dengan kepemilikan jamban keluarga dengan kategori pendidikan tinggi yang meliputi tamat SMA/Sarjana sebanyak $20,6 \%$ responden dan kategori pendidikan rendah yang meliputi tidak tamat SD, tamat SD dan tamat SMP sebanyak $79,4 \%$ responden.

d. Tidak ada keterkaitan antara pendapatan responden dengan kepemilikan jamban keluarga dengan kategori pendapatan sangat tinggi 1,6 $\%$ responden, kategori pendapatan tinggi $1,6 \%$ responden, kategori pendapatan sedang sebanyak $25,4 \%$ responden dan kategori pendapatan rendah sebanyak $71,4 \%$ responden.

\section{Saran}

a. Bagi Masyarakat Desa Bulu Ulaweng, agar masyarakat lebih meningkatkan pemahaman, kesadaran dan kemauan untuk memiliki jamban keluarga dengan cara rajin mengikuti penyuluhan yang dilakukan oleh pemerintah setempat.

b. Bagi Pemerintah, agar pemerintah setempat melakukan pengawasan yang lebih efektif kepada masyarakat dan memberikan penyuluhan tentang kesehatan lingkungan terutama masalah jamban keluarga serta melakukan penerapan STBM khusus pilar 1 yaitu stop buang air besar sembarangan.

\section{DAFTAR PUSTAKA}

Notoatmodjo, Soekidjo. 2014. IImu Perilaku Kesehatan. Jakarta: PT. Rineka Cipta.

Proverawati, Atikah dan Eni Rahmawati.2012,Perilaku Hidup bersih dan Sehat. Yogyakarta :Nuha Medika.

Slamet, Juli Soemirat. 1994. Kesehatan Lingkungan. Yogyakarta: Gadjah Mada University Press.

Suharno.2015. Hubungan Pengetahuan, Tingkat Pendidikan Dan Status Ekonomi Dengan Ketersediaan Jamban Keluarga Di Desa Cidenok Wilayah Kerja UPTD Puskesmas Sumberjaya Kabupaten Majalengka Tahun 2015.(Online), (ejournal.stikesypib.ac.id/file.php, diakses 22 Desember 2017).

Suyono Dan Budirman, 2010. IImu Kesehatan Masyarakat Dalam Konteks Kesehatan Lingkungan. Buku Kedokteran EGC.

Taha,La H.Abdurrivai,A,Ruhban, Haderiah, 2013, Kajian tingkat KualitasPermukiman kumuh Berdasarkan Kondisi Sarana Sanitasi di Kelurahan Banta-bantaeng Kecamatan Rappocini Kota Makassar: Sulolipu,No.25 Tahun XX Vol.1.Januari-Juni 2013 Hal.94-104.

Widyastutik, Otik. 2016. Faktor yang Berhubungan Dengan Kepemilikan Jamban Sehat Di Desa Malikian, Kalimantan Barat:Fakultas IImu Kesehatan Universitas Muhammadiyah Pontianak. (Online),(https://jurnal.unej.ac.id/index.php/IKESMA/article/download/5223/3956/, $\quad$ diakses 12 Desember 2017). 